\title{
Trabalho, População Negra e Pandemia: notas sobre os primeiros resultados da PNAD CovID-19 1,2
}

Tatiana Dias Silva ${ }^{3}$

Sandro Pereira Silva ${ }^{4}$

\section{INTRODUÇÃO}

O mercado de trabalho é o canal pelo qual se revela, de forma bastante contundente, a estrutura de desigualdades presente na dinâmica social. E como o Brasil detém níveis reconhecidamente altos de desigualdade socioeconômica quando confrontado com outros países, qualquer análise mais aprofundada desses indicadores deve levar em consideração esse ponto (Costa e Silva, 2020).

No âmbito das desigualdades promovidas direta ou indiretamente pelo racismo, elemento estrutural da sociedade, seus efeitos se agudizam em tempos de incertezas em diversos aspectos das condiçôes de vida da população, tanto no modo como distribuem os meios de enfrentamento às consequências das crises quanto na tendência a produzir resultados proporcionalmente desfavoráveis aos grupos já vulnerabilizados (Matijascic e Silva, 2014; IBGE, 2019).

É nesse contexto que, servindo-se dos primeiros dados apresentados pela Pesquisa Nacional por Amostra de Domicílios no âmbito da pandemia (PNAD Covid-19), desenvolvida pelo Instituto Brasileiro de Geografia e Estatística (IBGE), procuramos compartilhar algumas reflexôes acerca da condição laboral da população negra no Brasil. A PNAD Covid-19 visa captar tanto aspectos da crise sanitária quanto seus efeitos no mundo do trabalho a partir de um painel domiciliar, com informações obtidas por contato telefônico (IBGE, 2020). O questionário utilizado é composto de três seçôes: saúde, trabalho e rendimentos além do trabalho.

O texto encontra-se organizado da seguinte forma. Na seção 2, apresenta-se um panorama sucinto sobre as condições do mercado de trabalho brasileiro anteriormente aos efeitos da pandemia. $\mathrm{Na}$ seçáo 3, discutem-se alguns resultados das mudanças durante a pandemia e suas diferenças em termos raciais. Por fim, são tecidas as conclusões.

\section{MUNDO DO TRABALHO E TRANSFORMAÇÕES RECENTES NO BRASIL}

Nesta seção, chamamos a atenção para o fato de que a crise econômica resultante das medidas de enfrentamento à pandemia de Covid-19 incidiu sobre um cenário já debilitado da dinâmica recente da economia brasileira e, por conseguinte, do comportamento do mercado de trabalho nacional.

1. DOI: http://dx.doi.org/10.38116/bapi26art5

2. Este texto foi publicado anteriormente como Nota Técnica, disponível em: <https://www.ipea.gov.br/portal/images/stories/PDFs/nota_ tecnica/201110_diest_n_46.pdf>.

3. Técnica de planejamento e pesquisa na Diretoria de Estudos e Políticas do Estado, das Instituições e da Democracia (Diest) do Ipea. Doutora em administração pela Universidade de Brasília (UnB).

4. Técnico de planejamento e pesquisa na Diretoria de Estudos e Políticas Sociais (Disoc) do Ipea. Doutor em políticas públicas, estratégia e desenvolvimento pela Universidade Federal do Rio de Janeiro (UFRJ). 
Para uma breve síntese das transformações do panorama laboral, cabe destacar a recuperação da atividade econômica no período 2004-2014, quando a taxa média de crescimento anual do produto interno bruto (PIB) praticamente dobrou em relação à década anterior, aliada à manutenção de relativo controle do nível de preços e das finanças públicas. Com isso, os índices de desemprego apresentaram queda contínua, fechando 2014 com média de 6,5\%, medida pela PNAD à época. Os dados da Relação Anual de Informaçóes Sociais (Rais) registraram saldos líquidos anuais positivos de criaçáo de novos postos de emprego formal, com média de 1,8 milhão ao ano (a.a.) nesse mesmo período, acarretando quedas substanciais nos índices de informalidade (Silva, 2018). Paralelamente, outras decisôes de política pública, como a valorização real do salário mínimo e o fortalecimento de programas sociais, proporcionaram uma tendência virtuosa de redução das desigualdades de renda, conforme identificado por diversos autores (Kerstenetzky, 2019).

A economia brasileira, contudo, enfrentou logo em seguida uma forte recessão, com queda brusca no PIB entre 2015 e 2016 (em torno de 7\%, somados) e a manutenção de certa estagnaçáo nos três anos seguintes, crescendo em torno de 1\% a.a., além de apresentar seguidos deficit fiscais. Esse cenário impactou diretamente o mercado de trabalho, com a taxa de desemprego flutuando em patamares próximos ao dobro do que era no período pré-crise. Outras evidências indesejadas a partir de então foram elevaçóes nos seguintes indicadores: i) parcela da população em situação de desemprego de longa duração; ii) desemprego oculto por desalento; iii) parcela de trabalhadores ocupados subutilizados por insuficiência de horas trabalhadas; iv) desigualdade dos rendimentos do trabalho entre os indivíduos ocupados; e v) informalidade da força de trabalho ocupada (Ipea, 2020b).

Os dados dos primeiros meses de 2020, abordando justamente a transição para o reconhecimento da pandemia no Brasil (entre a primeira e a segunda quinzena de março), demonstram exacerbação da crise do mercado de trabalho. Até o final de maio, a população ocupada total já havia diminuído em torno de 7 milhôes de pessoas, comparada ao mesmo período do ano anterior, e no acumulado do ano até esse período, já se registrava um saldo negativo de mais de 1,1 milhão de empregos formais.

A taxa de desocupação estimada subiu de 11,8\% para 12,8\% entre fevereiro e maio de 2020 , e só não foi maior devido à queda substancial da taxa de participação da força de trabalho (de $62 \%$ para 56\%) no mesmo período, sobretudo em função da parcela da populaçáo sem emprego que deixou de buscar recolocação em razão das medidas necessárias de prevenção sanitária. Conforme identificou Hecksher (2020), os números da PNAD em abril revelavam que a população ocupada foi inferior a 50\%; ou seja, pela primeira vez desde que esse indicador é medido, o contingente de pessoas em idade ativa não ocupadas no país superava o de ocupadas.

As estimativas apontam queda absoluta da ocupação em torno de 9,9 milhóes entre fevereiro e maio de 2020, além de aumento da população desalentada (1,2 milhão) e diminuição dos ocupados com contribuição previdenciária (3,3 milhôes). Como resultado, a massa de rendimentos efetivamente recebidos apresentou redução de $\mathrm{R} \$ 37$ bilhóes, queda de $16,5 \% .{ }^{5}$ Os primeiros dados da PNAD Covid-19 já indicavam que 5,2\% dos domicílios brasileiros (cerca de 3,5 milhôes) sobreviveram ao mês de maio somente com os rendimentos recebidos do auxílio emergencial do governo federal, passando no mês seguinte para 6,5\% (4,5 milhóes de domicílios) (Carvalho, 2020; Ipea, 2020a).

5. Segundo Carvalho (2020), a queda da massa de rendimentos em função da pandemia é causada tanto pela diferença entre a massa salarial efetivamente recebida e a massa habitualmente recebida entre aqueles que permaneceram ocupados quanto pela perda de rendimentos daqueles que não tinham mais ocupação. 
Praticamente todos os setores econômicos registraram retração no nível do emprego em relação ao mesmo período do ano anterior, sendo que os mais afetados foram: comércio, construção civil, alimentação e alojamento, além da categoria de serviços domésticos, marcada fortemente por vínculos informais. Os únicos setores que não sofreram retração foram: agricultura, serviços para empresas (informação, comunicação e atividades financeiras, imobiliárias, profissionais e administrativas) e administração pública (Ipea, 2020a).

Em termos de segmentação populacional, todos os grupos demográficos foram atingidos pela crise. Contudo, algumas diferenças podem ser acentuadas, especialmente quando se foca no aspecto racial, componente estrutural do mercado de trabalho brasileiro (Ipea, 2012; 2014). A seção seguinte se atenta justamente a essas diferenças identificadas em termos raciais.

\section{POPULAÇÃO NEGRA E TRABALHO EM TEMPOS DE PANDEMIA}

A seguir, serão tratados os dados da PNAD Covid-19 em três aspectos considerados fundamentais no contexto da crise sanitária e seus respectivos impactos na condição laboral da populaçáo negra brasileira: i) desocupaçáo e informalidade; ii) afastamento temporário do trabalho e trabalho remoto; e iii) desemprego por desalento causado pela pandemia.

\subsection{Desocupação e informalidade}

As pessoas que se declararam pretas e pardas correspondiam em junho de 2020 a 54,9\% da força de trabalho, ${ }^{6}$ sendo $52,5 \%$ dos ocupados ${ }^{7}$ e $60,3 \%$ dos desocupados. Durante os primeiros meses da pandemia no país, a taxa de desocupaçáo cresceu para todos os grupos de cor ou raça, com média geral passando de $10,7 \%$ para 13,1\% entre maio e julho. Considerando-se somente a população negra - homens e mulheres -, essa elevaçáo foi ainda superior: passou de 10,7\% e 13,8\% para, respectivamente, $12,7 \%$ e $17,6 \%$ (tabela 1 ).

Quanto à ocupação informal, estima-se que 37,2\% dos ocupados estavam nessa situação em maio de 2020, sendo que a informalidade nas relações de trabalho incide majoritariamente sobre a população negra. As consequências dessa alta informalidade expóem os trabalhadores, de modo mais acentuado, aos riscos de uma atividade laboral com escassa regulamentaçáo e baixo acesso a mecanismos de seguridade social (seguro-desemprego, abono salarial e aposentadoria), além de submetê-los a maior volatilidade de renda e precariedade nos vínculos ocupacionais. Em tempos de crise, o risco de desocupação desprotegida intensifica o quadro de vulnerabilidades. Note-se também que uma leve redução da taxa de informalidade no mês de julho pode estar relacionada com a queda na taxa de participação da força de trabalho e o aumento da desocupação (tabela 1), ou seja, parte do contingente que estava na informalidade passa à situação de desocupação ou mesmo de inatividade.

\footnotetext{
6. Pessoas com 14 anos ou mais, ocupadas e desocupadas.

7. Considera-se ocupadas "as pessoas que, nesse período, trabalharam pelo menos uma hora completa em trabalho remunerado em dinheiro, produtos, mercadorias ou benefícios [...] ou em trabalho sem remuneração direta em ajuda à atividade econômica de membro do domicílio ou parente que reside em outro domicílio, ou, ainda, as que tinham trabalho remunerado do qual estavam temporariamente afastadas nessa semana" (IBGE, 2020, p. 8).
} 


\section{TABELA 1}

Dados de ocupação por cor ou raça e sexo (2020)

\begin{tabular}{|c|c|c|c|c|c|}
\hline Indicadores & Total & Mulheres negras & Mulheres brancas & Homens negros & Homens brancos \\
\hline & \multicolumn{5}{|c|}{ Maio } \\
\hline Pessoas na força de trabalho (1 mil) & 94.533 & 21.020 & 19.595 & 29.104 & 23.637 \\
\hline Taxa de participação (\%) & 55,6 & 44,6 & 49,6 & 63,6 & 66,7 \\
\hline Taxa de desocupação (\%) & 10,7 & 13,8 & 10,5 & 10,7 & 8,2 \\
\hline \multirow[t]{2}{*}{ Taxa de informalidade $(\%)$} & 37,2 & 41,4 & 31,8 & 41,6 & 32,7 \\
\hline & \multicolumn{5}{|c|}{ Junho } \\
\hline Pessoas na força de trabalho (1 mil) & 95.264 & 21.272 & 19.645 & 29.685 & 23.594 \\
\hline Taxa de participação (\%) & 56,0 & 44,9 & 49,7 & 64,5 & 66,8 \\
\hline Taxa de desocupação (\%) & 12,4 & 16,1 & 12,0 & 12,5 & 9,3 \\
\hline \multirow[t]{2}{*}{ Taxa de informalidade' $(\%)$} & 37,3 & 41,5 & 31,1 & 42,3 & 32,9 \\
\hline & \multicolumn{5}{|c|}{ Julho } \\
\hline Pessoas na força de trabalho (1 mil) & 93.737 & 20.598 & 19.141 & 29.391 & 23.540 \\
\hline Taxa de participação (\%) & 55,1 & 43,5 & 48,5 & 63,9 & 66,4 \\
\hline Taxa de desocupação (\%) & 13,1 & 17,6 & 13,0 & 12,7 & 9,5 \\
\hline Taxa de informalidade' (\%) & 36,2 & 39,3 & 29,2 & 41,9 & 32,2 \\
\hline
\end{tabular}

Com relação à média de todos os rendimentos do trabalho, os números da PNAD Covid-19 revelam que a renda média habitualmente recebida em junho representou $83 \%$ do valor obtido no mesmo mês do ano anterior (Carvalho, 2020). Essa diferença é ainda maior para os trabalhadores por conta própria $(63,4 \%)$ e dos empregados sem carteira do setor privado $(79,1 \%)$. Não se verificam diferenças significativas entre a perda salarial comparada entre brancos $(83,5 \%)$ e negros $(83,1 \%)$ em junho. Importa destacar, todavia, que se parte de bases bastante desiguais, uma vez que o rendimento médio efetivamente recebido de todos os trabalhos da população negra correspondia apenas a $61,5 \%$ do percebido pelos trabalhadores brancos em junho de 2020 (R $\$ 1.498$ contra $\mathrm{R} \$ 2.434$, respectivamente).

\subsection{Afastamentos e trabalho remoto}

Durante a pandemia e mediante as orientaçôes sanitárias, muitos estados e municípios implementaram medidas de distanciamento social (Sá, 2020; Moraes, 2020). Por um lado, os impactos dessas medidas na atividade econômica levaram várias empresas a encerrar ou diminuir suas atividades, reduzindo a demanda por trabalho. Por outro lado, essa reconfiguração do ordenamento produtivo impeliu muitas organizaçóes a revisar seus processos de trabalho, privilegiando, em alguns casos, o trabalho remoto. Com efeito, o modo como os indivíduos vivenciaram sua atividade laboral nesse período tem direta relação com as clivagens e hierarquias do mundo do trabalho, inclusive no tocante às desigualdades raciais (Costa e Silva, 2020). 
$\mathrm{Na}$ PNAD Covid-19, indagou-se se o indivíduo estava afastado temporariamente de algum trabalho. ${ }^{8}$ Em maio de 2020, 18,6\% dos ocupados encontravam-se nessa situaçáo em consequência do distanciamento social. Como pontuam Lameiras e Cavalcanti (2020), esse indicador seguiu em queda nos meses subsequentes, o que reflete a suspensão ou flexibilização de medidas de distanciamento social em curso até então.?

Nessa mesma pesquisa, a população negra, que correspondia a 52,3\% dos ocupados, representou $58,4 \%$ dos afastados temporariamente em maio. Essa sobrerrepresentação também é verificada nos meses seguintes. $\mathrm{O}$ afastamento foi mais intenso para o grupo das mulheres negras. Apesar de corresponderem a $21,5 \%$ do total de ocupados, elas representaram 30,9\% das pessoas afastadas temporariamente do trabalho. Como mostra a tabela 2, embora o percentual de afastamento tenha diminuído nos meses seguintes, o grupo das mulheres negras, em particular, permaneceu como o mais afetado pelo afastamento do trabalho.

TABELA 2

Pessoas ocupadas afastadas do trabalho devido ao distanciamento social, por sexo e cor ou raça

\begin{tabular}{|c|c|c|c|c|c|}
\hline Indicadores & Total & Mulheres negras & Mulheres brancas & Homens negros & Homens brancos \\
\hline & \multicolumn{5}{|c|}{ Maio } \\
\hline Pessoas ocupadas & 84.404 & 18.128 & 17.540 & 25.986 & 21.703 \\
\hline $\begin{array}{l}\text { Pessoas ocupadas e afastadas do trabalho devido ao } \\
\text { distanciamento social ( } 1 \text { mil pessoas) }\end{array}$ & 15.725 & 4.856 & 3.500 & 4.322 & 2.826 \\
\hline \multirow[t]{2}{*}{$\%$ do total de ocupados } & 18,6 & 26,8 & 20,0 & 16,6 & 13,0 \\
\hline & \multicolumn{5}{|c|}{ Junho } \\
\hline Pessoas ocupadas & 83.449 & 17.848 & 17.279 & 25.984 & 21.391 \\
\hline $\begin{array}{l}\text { Pessoas ocupadas e afastadas do trabalho devido ao } \\
\text { distanciamento social ( } 1 \text { mil pessoas) }\end{array}$ & 11.814 & 3.792 & 2.649 & 3.198 & 2.023 \\
\hline \multirow[t]{2}{*}{$\%$ do total de ocupados } & 14,2 & 21,2 & 15,3 & 12,3 & 9,5 \\
\hline & \multicolumn{5}{|c|}{ Julho } \\
\hline Pessoas ocupadas & 81.484 & 16.971 & 16.646 & 25.654 & 21.297 \\
\hline $\begin{array}{l}\text { Pessoas ocupadas e afastadas do trabalho devido ao } \\
\text { distanciamento social ( } 1 \text { mil pessoas) }\end{array}$ & 6.784 & 2.250 & 1.561 & 1.757 & 1.127 \\
\hline$\%$ do total de ocupados & 8,3 & 13,3 & 9,4 & 6,8 & 5,3 \\
\hline
\end{tabular}

A posição na ocupação explica parte dessas diferenças. Por exemplo, o trabalho doméstico informal (sem carteira) representava 3,8\% das ocupaçóes em maio, mas correspondia, nesse período, a $6,9 \%$ dos trabalhadores ocupados afastados temporariamente. Em outras palavras, foi uma categoria significativamente atingida durante a pandemia: o contingente de pessoas ocupadas no trabalho doméstico passou de 4.458 mil, em maio, para 3.946 mil em julho de 2020, uma perda estimada

8. "Consideram-se como ocupadas temporariamente afastadas de trabalho remunerado as pessoas que não trabalharam durante pelo menos uma hora completa na semana de referência por motivo de quarentena, isolamento, distanciamento social ou férias coletivas devido à pandemia; férias, folga, jornada variável ou licença remunerada (em decorrência de maternidade, paternidade, saúde ou acidente da própria pessoa, estudo, casamento, licença-prêmio etc.)" (IBGE, 2020, p. 8).

9. "Esse número, que foi, em média, 15,8 milhões em maio (18,7\% do total de pessoas ocupadas) e 11,8 milhões em junho (14,2\% do total), caiu para 5,8 milhões na semana de referência e atingiu, na média de julho, 6,8 milhões de pessoas (8,4\% do total de ocupados)" (Lameiras e Cavalcanti, 2020, p. 1). 
de $11,5 \%$ de postos de trabalho em três meses. Vale ressaltar que a categoria de trabalho doméstico é composta majoritariamente por mulheres (92,3\%), entre as quais 67,7\% são negras, com ampla e crescente atuação na modalidade de diaristas (Pinheiro, Tokarski e Vasconcelos, 2020).

Com efeito, as ocupaçóes com vínculos mais frágeis foram as mais afetadas pelo distanciamento social. Enquanto os empregados sem carteira do setor privado e por conta própria representavam 9,6\% e $29,0 \%$ dos ocupados, eram, respectivamente, $11,8 \%$ e $35,0 \%$ dos afastados em razão do distanciamento social. Pode-se também destacar alguns setores, sobre os quais a estratégia do distanciamento social teve maior impacto, considerando sua participação nos afastamentos temporários vis-à-vis sua participação no total das ocupaçóes: alojamento e alimentação $(8,5 \%$ versus $5,6 \%)$, serviços domésticos $(8,2 \%$ versus $5,3 \%)$ ou administraçáo pública, defesa e seguridade social $(21,5 \%$ versus $19,5 \%)$. Importa considerar que grande parcela dos afastamentos ocorreu sem qualquer remuneraçáo. ${ }^{10}$

No caso dos trabalhadores com contrato, parte deles pode ter tido suas jornadas suspensas ou reduzidas com base no Programa Emergencial de Manutenção do Emprego e da Renda (Lei no 14.020, conversão da Medida Provisória nº 936/2020). Dada a abrangência e a duraçáo limitadas dessa norma, e diante da redução das medidas de distanciamento social, é importante monitorar, neste caso, como esses vínculos são (ou não) reintegrados às atividades econômicas. Considerando-se o impacto da pandemia nas micro e pequenas empresas, segmento intensivo em trabalho (Nogueira, Silva e Carvalho, 2020), é plausível supor que uma parcela desses vínculos migre para a desocupação ou mesmo para fora da força de trabalho, em parte configurando-se em desemprego oculto por desalento causado pela pandemia.

O gráfico 1 traz informações acerca das horas de trabalho habituais e efetivas no mês de referência durante a pandemia. Como é possível verificar, as trabalhadoras negras foram as que tiveram maior redução de jornada de trabalho, com consequente repercussão nos rendimentos, já historicamente inferiores em relação a outros grupamentos de cor e sexo (Marcondes et al., 2013). Os dados mostram também que, mesmo entre os profissionais com nível superior, as mulheres negras foram as únicas que passaram a uma carga horária inferior a $70 \%$ da habitual. ${ }^{11}$

Por sua vez, mais de 8,7 milhóes de trabalhadores permaneceram exercendo sua atividade laboral de forma remota, correspondendo a 10,3\% dos ocupados em maio, com reduçáo dessa taxa nos meses seguintes. $\mathrm{O}$ trabalho remoto foi a realidade para $17,6 \%$ dos ocupados (não afastados) brancos e para apenas $9 \%$ dos negros nessa situação (tabela 3). Somente cerca de um terço do total de trabalhadores ocupados em atividade remota era composto de trabalhadores negros. Tal como os outros fenômenos analisados, essa distribuição varia conforme a posição na ocupação, os setores e atividades desempenhadas e a qualidade dos vínculos. Por exemplo, enquanto $31,1 \%$ das pessoas com nível superior completo ou pós-graduaçáo encontravam-se em trabalho remoto em julho, esta era a realidade para apenas $1,1 \%$ dos trabalhadores com fundamental completo ao médio incompleto.

10. "Foi verificado que entre os ocupados que estavam afastados do trabalho que tinham na semana de referência no Brasil (14,8 milhões), aproximadamente 7,1 milhões de pessoas estavam sem a remuneração do trabalho, este total representava 48,4\% do total de pessoas afastadas do trabalho que tinham, em maio este percentual chegou a 51,3\%" (IBGE, 2020, p. 3).

11. Vale ressaltar que, em relação à escolaridade, o único grupo sub-representado entre os afastados pelo distanciamento social, em comparação com sua participação no total da ocupação, é o de trabalhadores com formação superior ou com pós-graduação, que representavam 24,1\% dos ocupados em maio e 19,7\% dos afastados devido ao distanciamento social. Não por acaso, este é o grupo que mais permaneceu vinculado a suas ocupações por meio do trabalho remoto. 


\section{GRÁFICO 1}

Razão entre média de horas habitual e efetivamente trabalhadas, por sexo e cor ou raça (jun./2020)

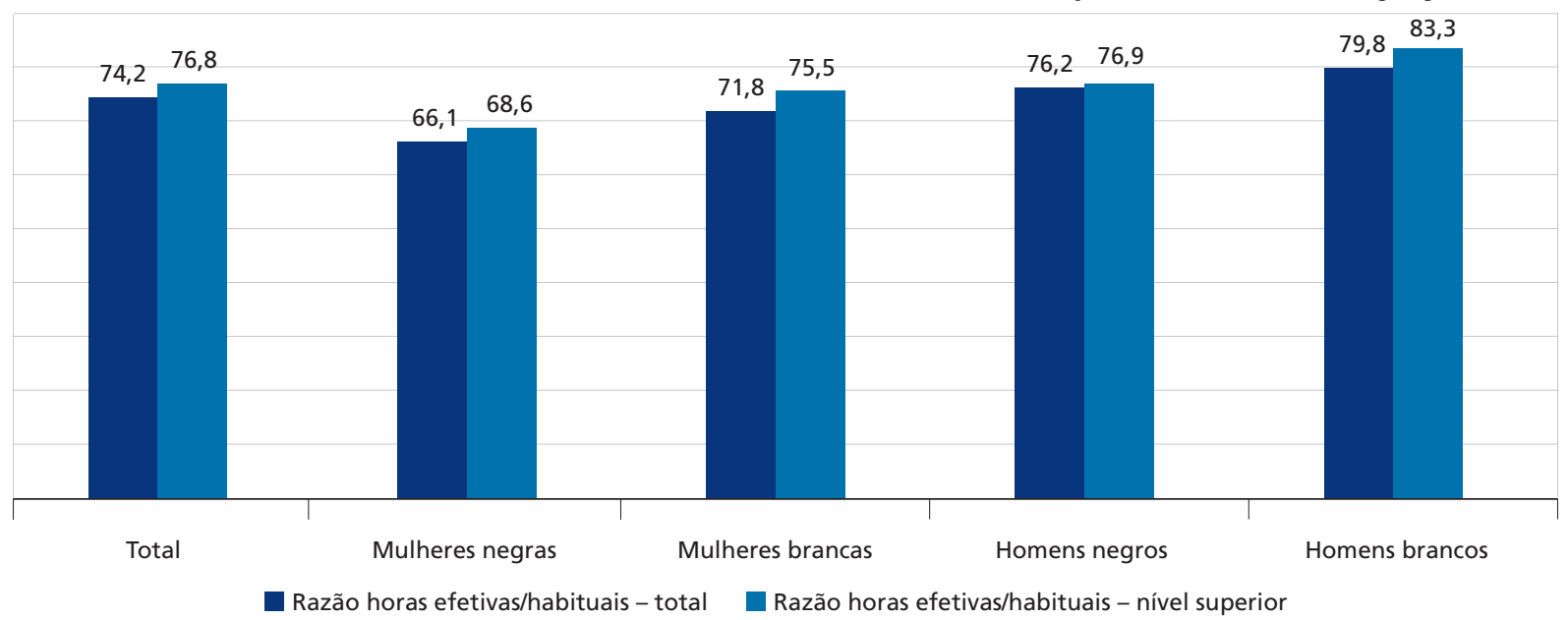

Fonte: PNAD Covid-19//BGE.

Obs.: Horas habitual e efetivamente trabalhadas em todos os trabalhos na semana de referência.

\section{TABELA 3}

Pessoas não afastadas do trabalho, que trabalhavam de forma remota (2020)

\begin{tabular}{|c|c|c|c|}
\hline Situação & Total & Brancos & Negros \\
\hline & & Maio & \\
\hline Pessoas ocupadas e não afastadas do trabalho, que trabalhavam de forma remota (1 mil pessoas e \%) & $\begin{array}{c}8.709 \\
(100,0)\end{array}$ & $\begin{array}{l}5.550 \\
(63,7)\end{array}$ & $\begin{array}{l}2.987 \\
(34,3)\end{array}$ \\
\hline \multirow[t]{2}{*}{$\begin{array}{l}\text { Pessoas ocupadas e não afastadas do trabalho, que trabalhavam de forma remota, no total da } \\
\text { população ocupada e não afastada do trabalho (\%) }\end{array}$} & 13,3 & 17,6 & 9,0 \\
\hline & & Junho & \\
\hline Pessoas ocupadas e não afastadas do trabalho, que trabalhavam de forma remota (1 mil pessoas e \%) & $\begin{array}{c}8.694 \\
(100,0)\end{array}$ & $\begin{array}{l}5.547 \\
(63,8)\end{array}$ & $\begin{array}{l}2.995 \\
(34,5)\end{array}$ \\
\hline \multirow[t]{2}{*}{$\begin{array}{l}\text { Pessoas ocupadas e não afastadas do trabalho, que trabalhavam de forma remota, no total da } \\
\text { população ocupada e não afastada do trabalho (\%) }\end{array}$} & 12,7 & 17,0 & 8,5 \\
\hline & & Julho & \\
\hline Pessoas ocupadas e não afastadas do trabalho, que trabalhavam de forma remota (1 mil pessoas e \%) & $\begin{array}{c}8.403 \\
(100,0)\end{array}$ & $\begin{array}{l}5.419 \\
(64,5)\end{array}$ & $\begin{array}{l}2.844 \\
(33,8)\end{array}$ \\
\hline $\begin{array}{l}\text { Pessoas ocupadas e não afastadas do trabalho, que trabalhavam de forma remota, no total da } \\
\text { população ocupada e não afastada do trabalho (\%) }\end{array}$ & 11,7 & 16,0 & 7,7 \\
\hline
\end{tabular}

\section{Fonte: PNAD Covid-19//BGE.}

No conjunto dos trabalhadores considerados essenciais, sobretudo nos setores de serviços, alimentação e saúde, conta-se com grande participação de trabalhadores negros, notadamente nas atividades operacionais e de menor remuneração. Não raro os trabalhadores desses segmentos, além de vivenciarem as consequências de vínculos precários, também reúnem menos recursos materiais para se proteger da Covid-19, dadas as condiçôes de habitação ou uso intensivo de transporte público. Caso sejam acometidos pela doença, também tendem a vivenciar maior dificuldade de tratamento, dadas as restriçóes econômicas para o acesso à saúde. 


\subsection{Desalento pela pandemia}

A busca por ocupação é fator-chave para entender o posicionamento dos indivíduos no mundo do trabalho e, consequentemente, nas suas estatísticas. Nesta subseção, o foco são as pessoas com 14 anos ou mais que não trabalharam no período de referência e não buscaram uma ocupação (ou seja, estavam fora da força de trabalho), mas gostariam de trabalhar, encontrando-se em condição de desemprego oculto por desalento.

Se o desalento se acentua em épocas de crise econômica, no cenário de pandemia, a falta de condiçóes e expectativas para buscar trabalho tende a ser agravada pelas circunstâncias sanitárias e seus efeitos. Conforme demonstrado na tabela 4 , em julho, 36,9\% da população acima de 14 anos fora da força de trabalho (inativa), cerca de 28 milhóes de pessoas, encontrava-se na situação de desalento. Desse conjunto, cerca de dois terços $(65,3 \%)$ correspondiam a indivíduos negros. Ressalta-se que $67,0 \%$ do total de desalentados atribui essa condiçáo à pandemia, o que chamamos neste texto de desalentados pela pandemia.

\section{TABELA 4}

Pessoas fora da força de trabalho na semana de referência (jul./2020)

\begin{tabular}{|c|c|c|c|c|c|c|c|c|}
\hline Situação & Total & $\begin{array}{c}\text { Mulheres } \\
\text { negras }\end{array}$ & $\begin{array}{l}\text { Mulheres } \\
\text { brancas }\end{array}$ & $\begin{array}{l}\text { Homens } \\
\text { negros }\end{array}$ & $\begin{array}{l}\text { Homens } \\
\text { brancos }\end{array}$ & Total & $\begin{array}{l}\text { Negros } \\
(\%)\end{array}$ & $\begin{array}{c}\text { Brancos } \\
(\%)\end{array}$ \\
\hline Fora da força de trabalho (1 mil pessoas) & 76.472 & 26.781 & 20.308 & 16.587 & 11.912 & 100,0 & 56,7 & 42,1 \\
\hline $\begin{array}{l}\text { Não procuraram trabalho, mas gostariam de trabalhar } \\
\text { na semana anterior (A) (1 mil pessoas) }\end{array}$ & 28.251 & 11.130 & 5.802 & 7.326 & 3.699 & 100,0 & 65,3 & 33,6 \\
\hline$\%$ das pessoas fora da força de trabalho & 36,9 & 41,6 & 28,6 & 44,2 & 31,0 & - & - & - \\
\hline $\begin{array}{l}\text { Não procuraram trabalho por conta da pandemia ou } \\
\text { por falta de trabalho na localidade, mas que gostariam } \\
\text { de trabalhar na semana anterior (B) (1 mil pessoas) }\end{array}$ & 18.932 & 7.170 & 3.528 & 5.449 & 2.591 & 100,0 & 66,7 & 32,3 \\
\hline$\%$ das pessoas fora da força de trabalho & 24,8 & 26,8 & 17,4 & 32,8 & 21,8 & - & - & - \\
\hline$\%$ desalentados pela pandemia (B/A) & 67,0 & 64,4 & 60,8 & 74,4 & 70,1 & - & - & - \\
\hline
\end{tabular}

Nesse sentido, os efeitos da crise sanitária têm se mostrado até então ainda mais perversos para a população negra. Essas transformações apontam intensificação tanto do deficit de oportunidades de inserção laboral quanto das já precárias relações de trabalho existentes, em grande parte, não cobertas por mecanismos de proteçáo social e/ou trabalhista dada a alta informalidade da qual estão acometidos.

\section{CONCLUSÃO}

As múltiplas e interseccionais desigualdades que pesam sobre a população negra têm se apresentado de modo intenso e se agravado durante esse tempo de pandemia. Além da atençáo aos efeitos diretos das condiçốes de saúde e de acesso a atendimento médico, as perspectivas de subsistência e inserção laboral mostram-se essenciais para, ao menos, não permitir a ampliaçáo das desigualdades raciais, tão marcantes e estruturantes no país.

A estratificação do mercado de trabalho, além de ser agudizada nesse período pandêmico, traz outras consequências. Além do aumento da desocupação, entre a população ocupada, foram os cidadáos pretos e pardos que, por um lado, mais sofreram afastamento do trabalho, e, por outro, 
menos se beneficiaram da manutenção do vínculo laboral por trabalho remoto. Ademais, formaram ampla maioria da capacidade laboral submetida à situação de desemprego oculto por desalento, em grande parte justificada pela impossibilidade de buscar emprego durante a pandemia.

Os dados debatidos, portanto, permitem constatar que a experiência do trabalho em tempos de pandemia tem se mostrado de modo distinto pelo conjunto dos trabalhadores, intensificando as desigualdades em termos de vínculo e proteção, em desfavor das pessoas que já vivenciavam condições de trabalho mais vulneráveis.

Desse modo, não bastasse a gravidade do quadro atual de desigualdades no universo laboral brasileiro, as perspectivas também tendem a se delinear de forma desigual caso não sejam enfrentadas pelas açóes governamentais. Ao ser apartada de atividades remuneradas, por desemprego ou por desalento, importante parcela da população tende a ampliar a demanda por serviços públicos e assistência social, estes já pressionados por restriçôes orçamentárias (Pinheiro et al., 2020). Na ausência (ou insuficiência) de redes de proteção social, o horizonte torna-se mais que preocupante.

Além de políticas de garantia de emprego e estímulo à atividade produtiva, especialmente nos setores intensivos em força de trabalho, a ampliação e o fortalecimento das redes de proteção social e trabalhista (Silva, 2020) mostram-se como medidas fundamentais a fim de se evitar que os efeitos atuais da crise conduzam à intensificação do já expressivo nível de desigualdade racial existente no mercado de trabalho.

\section{REFERÊNCIAS}

CARVALHO, S. S. Os efeitos da pandemia sobre os rendimentos do trabalho e o impacto do auxílio emergencial. Carta de Conjuntura, Brasília: Ipea, n. 48, 2020.

COSTA, B. L.; SILVA, M. A. (Org.). Desigualdade para inconformados: dimensões e enfrentamentos das desigualdades no Brasil. Porto Alegre: CEGOV, 2020.

HECKSHER, M. Valor impreciso por mês exato: microdados e indicadores mensais baseados na PNAD Contínua. Brasília: Ipea, 2020. (Nota Técnica, n. 62).

IBGE - INSTITUTO BRASILEIRO DE GEOGRAFIA E ESTATÍSTICA. Desigualdades sociais por cor ou raça no Brasil. Estudos e Pesquisas. Informação Demográfica e Socioeconômica, n. 41, 2019.

. Pesquisa Nacional por Amostra de Domicílios: PNAD Covid-19. Resultado mensal (junho 2020). Rio de Janeiro: IBGE, 2020.

IPEA - INSTITUTO DE PESQUISA ECONÔMICA APLICADA. Igualdade racial. Políticas Sociais: acompanhamento e análise. Brasília: Ipea, n. 20, 2012.

Igualdade racial. Políticas Sociais: acompanhamento e análise. Brasília: Ipea, n. 22, 2014. . Análise do mercado de trabalho. Mercado de Trabalho: conjuntura e análise, n. 69, 2020a. . Trabalho e renda. Políticas Sociais: acompanhamento e análise. Brasília: Ipea, n. 27, 2020b. 
KERSTENETZKY, C. Redistribuição no Brasil no século XXI. In: ARRETCHE, M.; MARQUES, E.; FARIA, A. P. (Org.). As políticas da política: desigualdade e inclusão nos governos do PSDB e PT. São Paulo: Editora Unesp, 2019.

LAMEIRAS, M. A. P.; CAVALCANTI, M. A. F. de H. PNAD Covid-19 - divulgação de 14/8/2020 principais destaques. Carta de Conjuntura, Rio de Janeiro: Ipea, n. 48, 3otrim., 2020.

MARCONDES, M. M. et al. Dossiê mulheres negras. Brasília: Ipea, 2013.

MATIJASCIC, M.; SILVA, T. D. Situação social da população negra por estado. Brasília: Ipea, 2014. MORAES, R. F. Medidas legais de incentivo ao distanciamento social: comparaçáo das políticas e governos estaduais e prefeituras das capitais no Brasil. Brasília: Ipea, 2020. (Nota Técnica, n. 16).

NOGUEIRA, M. O.; SILVA, S. P.; CARVALHO, S. S. Socorro governamental às pequenas unidades produtivas frente à atual pandemia. Brasília: Ipea, 2020. (Nota Técnica, n. 63).

PINHEIRO, L.; TOKARSKI, C.; VASCONCELOS, M. Vulnerabilidades das trabalhadoras domésticas no contexto da pandemia de Covid-19 no Brasil. Brasília: Ipea, 2020. (Nota Técnica, n. 75).

PINHEIRO, M. B. et al. O financiamento federal dos serviços socioassistenciais no contexto da Covid-19. Brasília: Ipea, 2020. (Nota Técnica, n. 80).

SÁ, E. B. A saúde pública e o enfrentamento da crise causada pelo coronavírus. Brasília: Ipea, 2020. (Nota Técnica, n. 68).

SANTOS, M. P. et al. População negra e Covid-19: reflexôes sobre racismo e saúde. Estudos Avançados, v. 34, n. 99, 2020.

SILVA, S. P. O panorama laboral brasileiro no contexto recente da economia latino-americana. Mercado de Trabalho: conjuntura e análise, n. 64, 2018.

Políticas de inclusão produtiva: o "elo perdido" da proteção social? Políticas Sociais: acompanhamento e análise. Brasília: Ipea, n. 27, 2020. 